\title{
Replication of Crohn's disease-associated AIEC within macrophages is dependent on TNF- $\alpha$ secretion
}

\author{
Marie-Agnès Bringer ${ }^{1,2}$, Elisabeth Billard ${ }^{1,2}$, Anne-Lise Glasser ${ }^{1,2}$, Jean-Frédéric Colombel ${ }^{3}$ \\ and Arlette Darfeuille-Michaud ${ }^{1,2}$
}

Adherent and invasive Escherichia coli (AIEC) associated with Crohn's disease are able to survive and to replicate extensively in active phagolysosomes within macrophages. AIEC-infected macrophages release large amounts of tumour necrosis factor-alpha (TNF- $\alpha$ ) and do not undergo cell death. The aim of the present study was to determine what benefit AIEC bacteria could gain from inducing the release of large amounts of TNF- $\alpha$ by infected macrophages and to what extent the neutralization of TNF- $\alpha$ could affect AIEC intramacrophagic replication. Our results showed that the amount of TNF- $\alpha$ released by infected macrophages is correlated with the load of intramacrophagic AIEC bacteria and their intracellular replication. TNF- $\alpha$ secretion was not related to the number of bacteria entering host cells because when the number of bacteria internalized in macrophage was decreased by blocking lipid raft-dependent and clathrin-coated pits-dependent endocytosis, the amount of TNF- $\alpha$ secreted by infected macrophages was not modified. Interestingly, dose-dependent increases in the number of intracellular AIEC LF82 bacteria were observed when infected macrophages were stimulated with exogenous TNF- $\alpha$, and neutralization of TNF- $\alpha$ secreted by AIEC-infected macrophages using anti-TNF- $\alpha$ antibodies induced a significant decrease in the number of intramacrophagic bacteria. These results indicate that AIEC bacteria use TNF- $\alpha$ as a Trojan horse to ensure their intracellular replication because replication of AIEC bacteria within macrophages induces the release of TNF- $\alpha$, which in turn increases the intramacrophagic replication of AIEC. Neutralizing TNF- $\alpha$ secreted by infected macrophages may represent an effective strategy to control AIEC intracellular replication.

Laboratory Investigation (2012) 92, 411-419; doi:10.1038/labinvest.2011.156; published online 31 October 2011

KEYWORDS: adherent-invasive E. coli; anti-TNF- $\alpha$; Crohn's disease; macrophages; tumour necrosis factor-alpha (TNF- $\alpha$ )

Crohn's disease $(\mathrm{CD})$ and ulcerative colitis are two major forms of idiopathic inflammatory bowel diseases, with a combined prevalence of about $150-200$ cases per 100000 in the Western countries. They are multifactorial diseases, occurring in individuals with genetic predisposition in whom an environmental and/or infectious trigger causes an abnormal immune response. ${ }^{1,2}$ The theory of dysregulated host responses to intracellular microorganisms is emerging as a contributing factor in $\mathrm{CD}$ pathogenesis. The identification of the NOD2 (nucleotide-binding oligomerization domain 2) gene and the autophagy genes, ATG16L1 and IRGM, which are involved in the recognition and the elimination of intracellular bacteria, as susceptibility genes contributing to
CD strengthen the hypothesis of the involvement of invasive bacteria in the ileal form of $\mathrm{CD} .^{3-8}$

The presence of intramucosal Escherichia coli or mucosaassociated E. coli with invasive properties in CD patients has been reported in independent studies performed in the Europe and the United States. ${ }^{9-14} \mathrm{CD}$-associated E. coli are highly adherent and invasive, and accordingly they were termed adherent-invasive E. coli (AIEC). ${ }^{15}$ They form a biofilm on the surface of the ileal mucosa owing to abnormal expression of the specific host receptor CEACAM6 recognizing type 1 pili variant expressed by $\mathrm{CD}$-associated E. coli bacteria. ${ }^{16,17}$ Recent data showed that AIEC bacteria are able to target $\mathrm{M}$ cells on Peyer's patches through the expression of long polar fimbriae,

\footnotetext{
Clermont Université, Université d'Auvergne, JE2526, Clermont-Ferrand, France; ${ }^{2}$ Institut National de Recherche Agronomique, INRA USC-2018, Clermont-Ferrand, France and ${ }^{3}$ INSERM U795, Université Lille II, Département d'Hépatogastroentérologie, Claude Huriez Hospital, Lille, France Correspondence: Professor A Darfeuille-Michaud, University of Auvergne, Pathogénie Bactérienne Intestinale, CBRV, 28 Place Henri Dunant, F-63000 Clermont-Ferrand, France. 
allowing them to translocate across the intestinal epithelial barrier ${ }^{18}$ and that defects in autophagy linked to mutations in ATG16L1, IRGM and NOD2 favour AIEC replication within epithelial cells and dendritic cells. ${ }^{19-21}$

Macrophages serve as the first line of defence by ingesting and destroying invading microorganisms by means of a vast and sophisticated arsenal of microbicidal features. Although most bacteria are successfully internalized and eliminated by macrophages, many pathogenic bacteria have developed survival strategies that interfere with the internalization and/ or phagosomal maturation processes. ${ }^{22}$ AIEC bacteria are able to survive and to replicate extensively within macrophages. ${ }^{23}$ The bacteria replicate in large vacuoles that have phagolysosome-like properties within macrophages, where they are exposed to low $\mathrm{pH}$ and to the degradative activity of cathepsin D. ${ }^{24}$ AIEC-infected macrophages release large amounts of tumour necrosis factor-alpha $(\mathrm{TNF}-\alpha){ }^{23}$ Pathogen-induced apoptosis of macrophages is a common end for pathogenic strategies, ${ }^{25}$ but AIEC-infected macrophages do not undergo cell death. ${ }^{23}$ This probably results in the formation of granulomas, as observed with the in vitro model of human granulomas, in which AIEC LF82 induces aggregation of infected macrophages, and sometimes their fusion to form multinucleated giant cells, and subsequent recruitment of lymphocytes. ${ }^{26}$ Secretion of TNF- $\alpha$ by infected monocytes/macrophages is a common feature of pathogenic bacteria, but impaired macrophage TNF- $\alpha$ secretion has been reported following infection with some of them such as Brucella spp., meningitidis-associated E. coli K1, and Francisella tularensis. ${ }^{27-29}$ In addition, TNF- $\alpha$ can have opposite effects on intracellular bacteria replication. It allows the multiplication of intramacrophagic Mycobacterium tuberculosis ${ }^{30}$ or can provide a suppressive environment for certain pathogenic bacteria such as Legionella pneumophila, Coxiella burnetii and Brucella spp. by inhibiting their intracellular replication. ${ }^{31-35}$

The aim of the present study was to determine (i) what benefit AIEC bacteria could gain from the release of high amounts of TNF- $\alpha$ by infected macrophages and (ii) to what extent the neutralization of TNF- $\alpha$ could affect the intramacrophagic replication of AIEC bacteria.

\section{MATERIALS AND METHODS}

\section{Bacterial Strains and Plasmids}

AIEC strain LF82 was isolated from a chronic ileal lesion of a patient with CD. The LF82 fim mutant harbouring Tn5phoA transposon in fimA does not synthesize type 1 pili. ${ }^{36}$ The LF82- $\Delta h$ trA isogenic mutant is unable to replicate within J774 macrophages. ${ }^{37}$ Salmonella enterica serovar Typhimurium strain LT2 was used in this study. ${ }^{38}$ Plasmid pFPV25.1, which encodes the green fluorescent protein (GFP), was used to visualize bacteria for confocal microscopy analysis. ${ }^{39}$

\section{Cell Culture}

The murine macrophage-like cell line J774 (American Type Culture Collection no. TIB67) was maintained in an atmosphere containing $5 \% \mathrm{CO}_{2}$ at $37^{\circ} \mathrm{C}$ in RPMI 1640 medium (Lonza, Saint Beauzire, France) supplemented with $10 \%(\mathrm{vol} / \mathrm{vol})$ fetal calf serum (FCS; Lonza) and $1 \%$ L-Glutamine (Lonza).

\section{Antibodies and Reagents}

Goat antibodies against mouse TNF- $\alpha$ for the neutralization of TNF- $\alpha$ bioactivity were purchased from R\&D Systems (Lille, France). Mouse $\mathrm{IgG}_{1}$ isotype control antibodies were obtained from DSHB (Iowa, USA). Goat antibodies against clathrin were obtained from Sigma. Rabbit antiserum against E. coli lipopolysaccharide (LPS) O83 was generously provided by Lothar Beutin (Department of Biological Safety, Robert Koch Institut, Berlin, Germany). FITC-conjugated anti-goat IgG and Cy3-conjugated anti-rabbit IgG (Molecular Probes, Interchim, Montluçon, France) were used as secondary antibodies. FITC-labelled cholera toxin B (CTX B) subunit was obtained from Sigma. Vacuolar $\mathrm{pH}$-neutralizing reagents (chloroquine (CQ) and ammonium chloride $\left(\mathrm{NH}_{4} \mathrm{Cl}\right)$ ) were obtained from Sigma. Tetramethyl rhodamine isothiocyanate-labelled phalloidin and E. coli LPS O111:B4 were obtained from Sigma. TNF- $\alpha$ and IFN- $\gamma$ were obtained from R\&D Systems and ImmunoTools, respectively.

\section{Gentamicin-Killed Bacteria}

AIEC bacteria were suspended at DO $=0.1$ in PBS and were incubated for $30 \mathrm{~min}$ with gentamicin at $5 \mathrm{mg} / \mathrm{ml}$ before macrophages infection. Killing of bacteria was checked by plating on LB agar.

\section{Macrophage Uptake and Survival Assays}

J774 macrophages were seeded in 24-well tissue culture plates at a density of $2 \times 10^{5} \mathrm{cells} / \mathrm{cm}^{2}$. Internalization of bacteria within cells and the ability of bacteria to survive within macrophages were determined by the gentamicin protection assay. ${ }^{37}$ When not stated, J774 monolayers were infected at a multiplicity of infection (MOI) of 100 bacteria per macrophage. After $10 \mathrm{~min}$ of centrifugation at $1000 \mathrm{~g}$ and a $10 \mathrm{~min}$ incubation period at $37^{\circ} \mathrm{C}$ with $5 \% \mathrm{CO}_{2}$, fresh cell culture RPMI 1640 medium supplemented with $10 \%$ heat-inactivated FCS and containing $20 \mu \mathrm{g} / \mathrm{ml}$ of gentamicin was added for a period of $40 \mathrm{~min}$ ( $1 \mathrm{~h}$ post infection) or $24 \mathrm{~h}(24 \mathrm{~h}$ post infection) and the number of intracellular bacteria was determined as previously described. ${ }^{37}$

\section{Macrophage Uptake Inhibition}

Cell monolayers were washed twice with PBS and the medium was replaced with $1 \mathrm{ml}$ of RPMI 1640 without FCS and containing the given drug. Cells were pre-treated with chlorpromazine (CPZ; Sigma) at concentrations of 2.5, 5 and $10 \mu \mathrm{g} / \mathrm{ml}$, and with methyl- $\beta$-cyclodextrin (M $\beta \mathrm{CD}$; Sigma) at concentrations of 5 and $10 \mathrm{mM}$ for $1 \mathrm{~h}$ before infection. Macrophages were infected as described above. 


\section{Treatment with Vacuolar pH-Neutralizing Reagents}

Macrophages were infected as described above. $\mathrm{NH}_{4} \mathrm{Cl}$ (Sigma) at $30 \mathrm{mM}$ and CQ (Sigma) at $10 \mu \mathrm{M}$ were used to neutralize the vacuolar $\mathrm{pH}$. The reagents were added to cells at $1 \mathrm{~h}$ post infection. Infected and untreated cells were analyzed in parallel.

\section{Supplementation with Exogenous TNF- $\alpha$ and IFN- $\gamma$}

Macrophages were infected as described above. TNF- $\alpha$ at 10, 25 and $50 \mathrm{ng} / \mathrm{ml}$ was added to cells after infection in the medium containing gentamicin. Macrophages were pre-treated with IFN- $\gamma$ at $100 \mathrm{U} / \mathrm{ml}$ for $12 \mathrm{~h}$ before AIEC infection, and IFN- $\gamma$ was maintained along experiments. Infected and untreated cells were analyzed in parallel.

\section{TNF- $\alpha$ Neutralization}

Macrophages were infected as described above. Anti-TNF- $\alpha$ antibodies and isotype antibodies at $1 \mu \mathrm{g} / \mathrm{ml}$ were added during infection and after infection in the medium containing gentamicin. Infected and untreated cells were analyzed in parallel.

\section{Enzyme-Linked Immunosorbent Assay for TNF- $\alpha$ Quantification}

Macrophages seeded in 24-well tissue culture plates at a density of $1 \times 10^{5} \mathrm{cells} / \mathrm{cm}^{2}$ were infected at an MOI of 100 as described above. At $24 \mathrm{~h}$ post infection, supernatants were collected, centrifuged and stored at $-80^{\circ} \mathrm{C}$. As a positive control of induced TNF- $\alpha$ secretion, cells were stimulated with $1 \mu \mathrm{g}$ of $E$. coli O111:B4 LPS (Sigma) per ml. The amount of TNF- $\alpha$ released in the culture supernatant was determined by enzyme-linked immunosorbent assay (ELISA; R\&D systems). The optical density was determined at a wavelength of $450 \mathrm{~nm}$, and cytokine concentrations were assessed according to the manufacturer's instructions.

\section{Confocal Microscopy}

To detect localization of GM1 gangliosides, macrophage monolayers were incubated for $40 \mathrm{~min}$ at room temperature with CTX B at $10 \mu \mathrm{g} / \mathrm{ml}$ and then fixed. When necessary, the actin cytoskeleton was stained for $15 \mathrm{~min}$ with TRITClabelled phalloidin at $1 \mu \mathrm{g} / \mathrm{ml}$ (Sigma). To determine the percentage of positive AIEC LF82-containing phagosomes for a specific marker, at least 100 bacteria-containing phagosomes were counted and scored for the presence or absence of the marker protein. Cells were observed with a Zeiss LSM 510 Meta confocal microscope (ICCF, IFR79 Santé Université d'Auvergne, Clermont-Ferrand, France). Each confocal microscopy image is representative of three independent experiments.

\section{Cell Viability}

For each drug used in this study, macrophage viability was checked by Trypan blue dye exclusion assays and by measurement of lactate dehydrogenase release. ${ }^{23}$

\section{Statistical Analysis}

Student's $t$ test was used for comparison of the two groups of data. All experiments were done at least three times. A $P$-value of $\leq 0.05$ was considered statistically significant.

\section{RESULTS}

TNF- $\alpha$ Production by AIEC LF82-Infected Macrophages is Related to the Number of Intracellular Bacteria

A phenotypic characteristic of AIEC bacteria is their ability to induce the secretion of TNF- $\alpha$ by infected macrophages. ${ }^{23}$ The secretion of TNF- $\alpha$ was analyzed according to the MOI of macrophages with AIEC bacteria. TNF- $\alpha$ quantification at $24 \mathrm{~h}$ post infection in the supernatant of AIEC LF82-infected macrophages indicated a MOI-dependent increase (Figure 1a) and, as shown in Figures $1 \mathrm{~b}$ and $\mathrm{c}$, the amount of TNF- $\alpha$ released was related to the number of bacteria entering and replicating within macrophages. When infections were performed with gentamicin-killed bacteria to determine the part of TNF- $\alpha$ secreted by AIEC-infected macrophages related to extracellular pattern recognition receptor (PRR) stimulation by bacteria, we observed that the amount of TNF- $\alpha$ secreted was significantly lower than that observed with macrophages infected with live AIEC bacteria (Figure 1d). This indicated that TNF- $\alpha$ secretion in response to AIEC infection is dependent on extracellular PRR stimulation but also on intramacrophagic AIEC bacteria stimulation.

AIEC bacteria are able to greatly replicate within macrophages without escaping from the phagosome. ${ }^{23}$ An acidic environment is required for the intracellular replication of AIEC bacteria. ${ }^{24}$ To determine whether TNF- $\alpha$ production by infected macrophage is related to the ability of AIEC LF82 bacteria to replicate intracellularly, macrophages were treated with $\mathrm{NH}_{4} \mathrm{Cl}$ and $\mathrm{CQ}$, two vacuolar $\mathrm{pH}$-neutralizing agents previously shown to decrease the replication of intracellular AIEC LF82 bacteria (Figure 2a). Interestingly, the blockade of AIEC bacteria replication by neutralization of the intravacuolar $\mathrm{pH}$ decreased TNF- $\alpha$ secretion by macrophages in comparison to that of untreated macrophages (Figure $2 \mathrm{~b}$ ). We also analyzed the amount of TNF- $\alpha$ released at $24 \mathrm{~h}$ post infection by macrophages infected with the LF82- $\Delta$ htrA isogenic mutant. As previously reported, ${ }^{37}$ this mutant is not affected in its ability to enter macrophages (Supplementary Figure S1a) but is unable to replicate intracellularly (Figure 2a and Supplementary Figure S1b). In correlation with the absence of intramacrophagic bacteria replication, we observed that the amount of TNF- $\alpha$ released by macrophages infected with this mutant was reduced compared with that of macrophages infected with the wild-type strain LF82 and similar to that observed with LPS stimulated macrophages (Figure 2b). Of note, we observed that the vacuolar $\mathrm{pH}$-neutralizing agents $\mathrm{CQ}$ and $\mathrm{NH}_{4} \mathrm{Cl}$ were very potent inducers of killing of non-replicating AIEC intramacrophagic mutant and suppressors of TNF- $\alpha$ release (Supplementary Figure S2). Together, these results indicated that a part of TNF- $\alpha$ secreted by AIEC-infected macrophages is related to the number of intramacrophagic AIEC bacteria. 

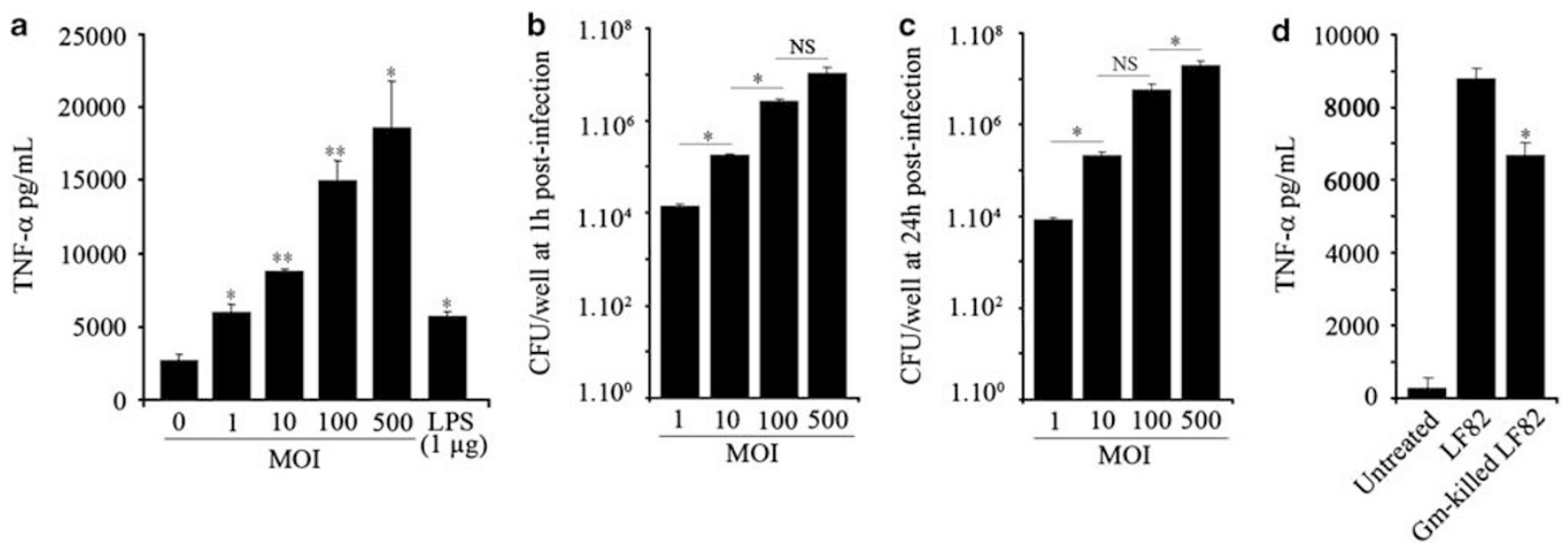

Figure 1 Tumour necrosis factor-alpha (TNF- $\alpha$ ) secretion by AIEC-infected macrophages. (a) Multiplicity of infection (MOI)-dependent TNF- $\alpha$ secretion by AIEC-infected macrophages. TNF- $\alpha$ secretion was measured by enzyme-linked immunosorbent assay (ELISA) in cell supernatants at $24 \mathrm{~h}$ post infection. Macrophages were treated with $1 \mu \mathrm{g}$ of $E$. coli lipopolysaccharide (LPS) as a positive control. (b) MOI-dependent numbers of AIEC bacteria that enter macrophages. Results are expressed as colony forming units (CFU) per well at $1 \mathrm{~h}$ post infection. (c) MOI-dependent numbers of intracellular bacteria LF82. Results are expressed as CFU per well at $24 \mathrm{~h}$ post infection. (d) TNF- $\alpha$ secretion by macrophages infected with live or gentamicin (Gm)-killed AIEC bacteria. Data are means \pm s.e.m. ${ }^{*} P<0.05,{ }^{*} p<0.01$. NS, non significant.

a
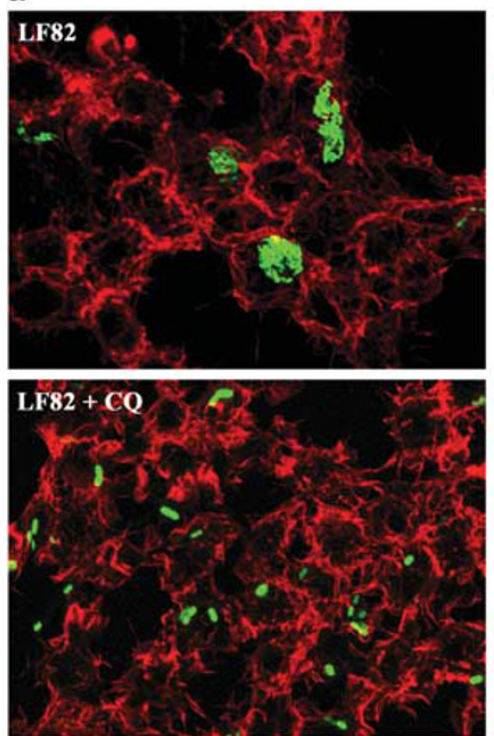
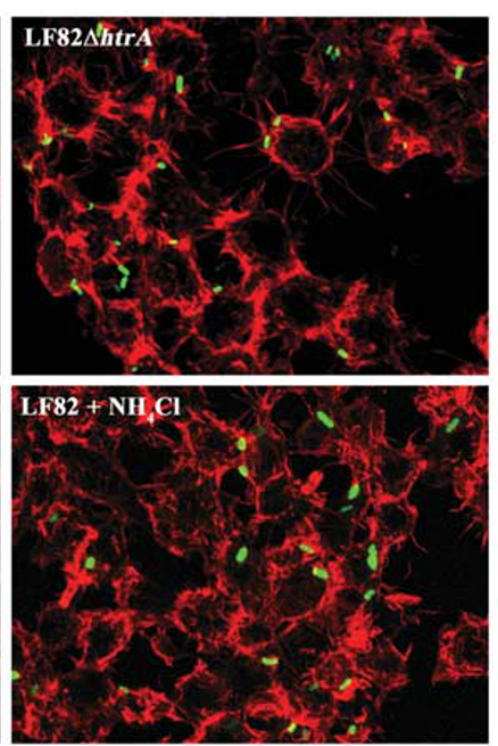

b

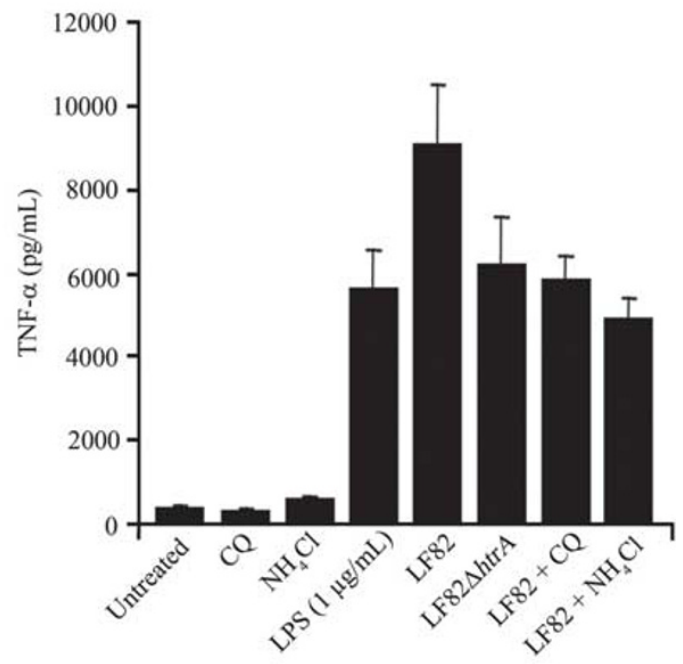

Figure 2 The blockade of intracellular replication of AIEC bacteria limits TNF- $\alpha$ secretion by infected macrophages. (a) Confocal microscopic examinations at $24 \mathrm{~h}$ post infection of macrophages infected with GFP-expressing bacteria, AIEC strain LF82 or the isogenic LF82- $\Delta$ htrA mutant, which is unable to replicate within macrophages, or treated with two vacuolar $\mathrm{pH}$-neutralizing agents, chloroquine (CQ) at $10 \mu \mathrm{M}$ and ammonium chloride $\left(\mathrm{NH}_{4} \mathrm{Cl}\right)$ at $30 \mathrm{mM}$. Actin cytoskeleton of cells was stained using TRITC-labelled phalloidin. (b) TNF- $\alpha$ secretion quantified by enzyme-linked immunosorbent assay (ELISA) in supernatants of uninfected macrophages or macrophages infected with AIEC strain LF82 or the non-replicative LF82- $\Delta h$ trA mutant, at $24 \mathrm{~h}$ post infection. When indicated, macrophages were treated with $1 \mu \mathrm{g}$ of E. coli lipopolysaccharide (LPS), CQ at $10 \mu \mathrm{M}$ or $\mathrm{NH}_{4} \mathrm{Cl}$ at $30 \mathrm{mM}$.

Data are means \pm s.e.m. for at least three independent experiments.

\section{Inhibition of AIEC LF82 Endocytosis Decreased the Numbers of AIEC LF82 Bacteria Internalized within Macrophages, but Does Not Interfere with the Secretion of TNF- $\alpha$}

Many pathogenic bacteria enter host cells by hijacking lipid raft and clathrin-coated pit endocytic pathways. ${ }^{40,41}$ The entry of AIEC LF82 bacteria involves lipid rafts as we observed that CTX B subunit, a drug that binds the GM1 gangliosides known to be clustered in lipid rafts, was recruited and accumulated around AIEC LF82 entering bacteria (Figure 3a). This was confirmed by treatment of macrophages with $\mathrm{M} \beta \mathrm{CD}$, a cholesterol-depleting molecule that induced a 1.9-fold decrease in the number of LF82 bacteria internalized in macrophages (Figure 3b). 
a
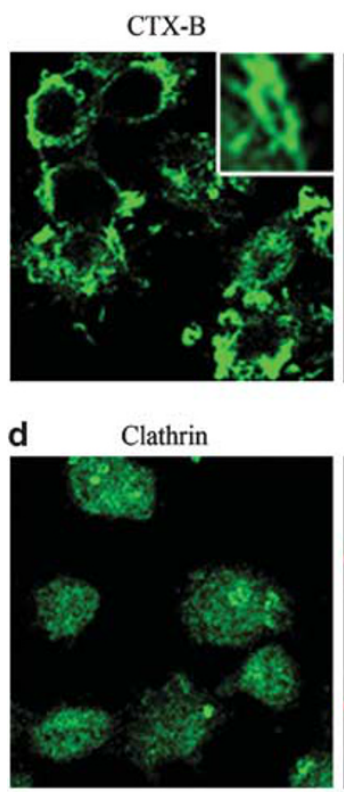

AIEC LF82
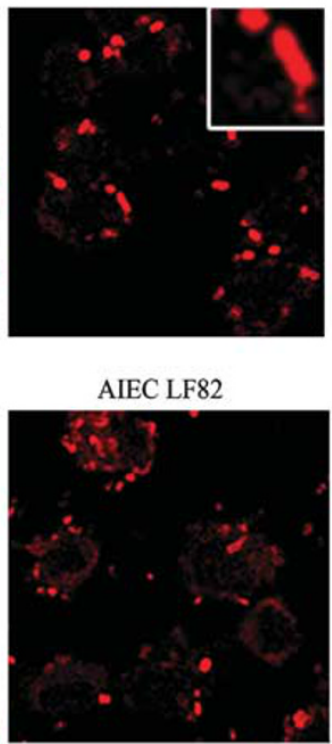
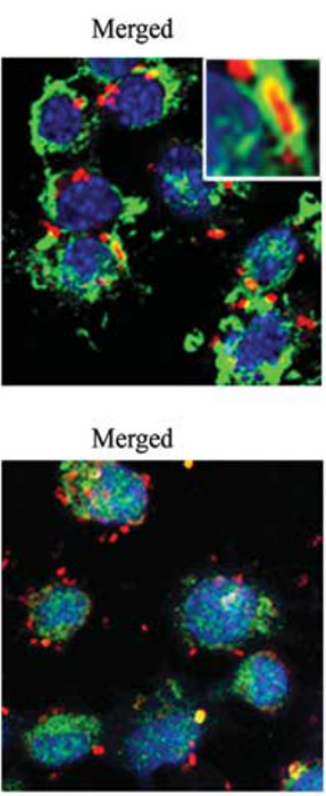
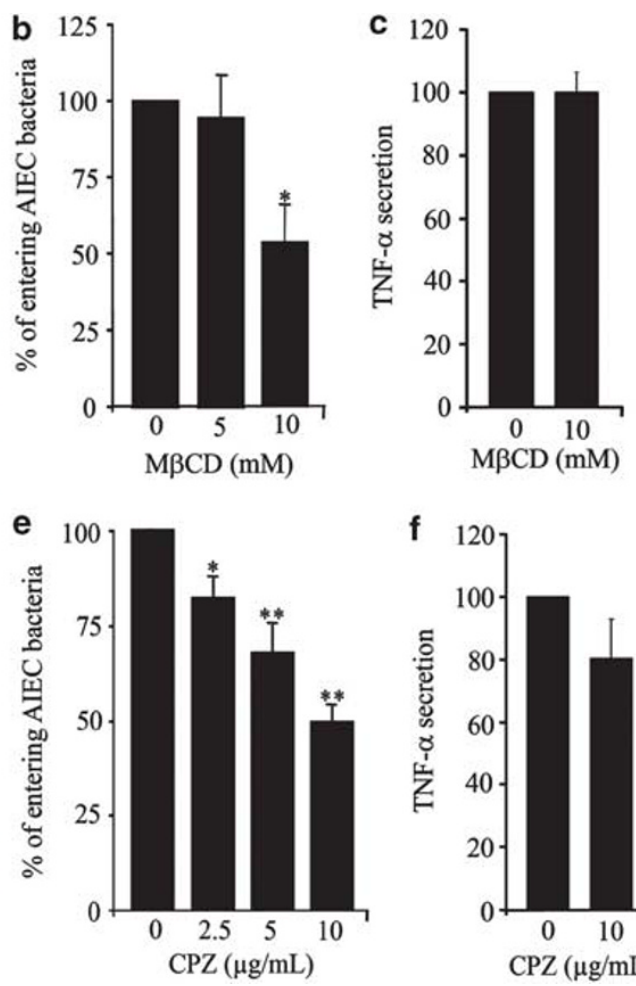

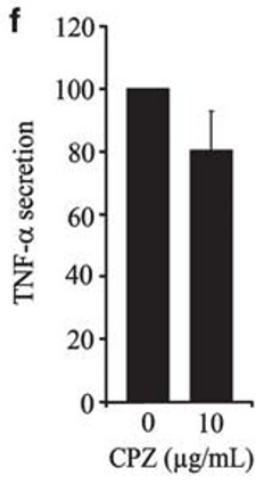

Figure 3 TNF- $\alpha$ secretion by AIEC LF82-infected macrophages after blockade of the lipid raft-dependent or the clathrin-coated pits-dependent endocytosis. (a) Confocal microscopic examinations of macrophages infected with AIEC LF82 bacteria at 20 min post infection. GM1 gangliosides were probed with FITC-labelled cholera toxin B (CTX B) subunit. AIEC LF82 bacteria were revealed using rabbit antiserum directed against lipopolysaccharide O83. (b) Effect of methyl- $\beta$-cyclodextrin (M $\beta C D$ ) on internalization of AIEC LF82 bacteria. Cells were pre-treated with M $\beta C D$ at concentrations of 5 and $10 \mathrm{mM}$ for $1 \mathrm{~h}$ before infection. The level of bacterial internalization was determined at $1 \mathrm{~h}$ post infection. Results are expressed as percentage of the number of internalized bacteria in drug-treated cells relative to that in non-treated cells, taken as $100 \%$. (c) TNF- $\alpha$ secretion by AIEC LF82-infected macrophages. Cells were treated with $M \beta C D$ at $10 \mathrm{mM}$ for $1 \mathrm{~h}$ before AIEC LF82 infection. TNF- $\alpha$ secretion was quantified by enzyme-linked immunosorbent assay (ELISA) in cell supernatants at $24 \mathrm{~h}$ post infection. Results are expressed as percentage of TNF- $\alpha$ secreted by drug-treated cells relative to that of untreated cells, taken as $100 \%$. (d) Confocal microscopic examinations of macrophages infected with AIEC LF82 bacteria at 20 min post infection. Labelling of clathrin was performed using goat antibodies against the murine clathrin. AIEC LF82 bacteria were revealed as in panel a. (e) Effect of chlorpromazine (CPZ) on internalization of AIEC LF82 bacteria. Cells were treated with CPZ at concentrations of $2.5,5$ and $10 \mu \mathrm{g} / \mathrm{ml}$ for $1 \mathrm{~h}$ before infection. Results are expressed as in panel b. (f) Cells were treated with CPZ at $10 \mu \mathrm{g} / \mathrm{ml}$ for $1 \mathrm{~h}$ before AIEC LF82 infection. TNF- $\alpha$ secretion was quantified as in panel c. Data are means \pm s.e.m. ${ }^{\star} P<0.05,{ }^{* * P}<0.01$.

In addition, AIEC bacteria used clathrin-dependent endocytosis to enter macrophages, as confocal microscopy experiments using an antibody directed against clathrin showed that after 20 min of infection, $37.5 \pm 2.8 \%$ of AIEC LF82 bacteria colocalized with clathrin (Figure 3d). Clathrindependent endocytosis of AIEC bacteria was confirmed by pre-treatment of macrophages with increased concentrations of $\mathrm{CPZ}$ that induced dose-dependent decreases in the numbers of AIEC LF82 bacteria internalized within macrophages (Figure 3e). These experiments indicated that both lipid raft- and clathrin-coated pit-mediated endocytosis are involved in the entry of AIEC LF82 within macrophages. However, there was no significant difference between the amounts of TNF- $\alpha$ secreted by AIEC-infected macrophages treated with drugs inhibiting lipid raft- or clathrin-coated pit-mediated endocytosis and by untreated macrophages (Figures $3 \mathrm{c}$ and $\mathrm{f}$ ). These results indicated that the amount of
TNF- $\alpha$ secreted by AIEC-infected macrophages was not related to the number of bacteria entering host cells.

\section{The Amount of TNF- $\alpha$ Released by AIEC LF82-Infected Macrophages is Related to Intracellular Bacteria Replication}

The amount of TNF- $\alpha$ secreted following cell infection by the LF82 non-piliated mutant 52D11 was compared with that obtained for LF82-infected macrophages as we observed that this mutant was internalized 2.4-fold less efficiently within macrophages than the wild-type strain LF82 (Figure 4a) and that the percentages of intracellular bacteria at $24 \mathrm{~h}$ post infection relative to $1 \mathrm{~h}$ post infection were not significantly different $(P>0.05)$ for the wild-type strain LF82 and for the 52D11 mutant (Figures $4 \mathrm{~b}$ and $\mathrm{c}$ ). No significant difference $(P>0.05)$ in the level of secreted TNF- $\alpha$ was also observed in the supernatant of 52D11 mutant- and AIEC LF82-infected 

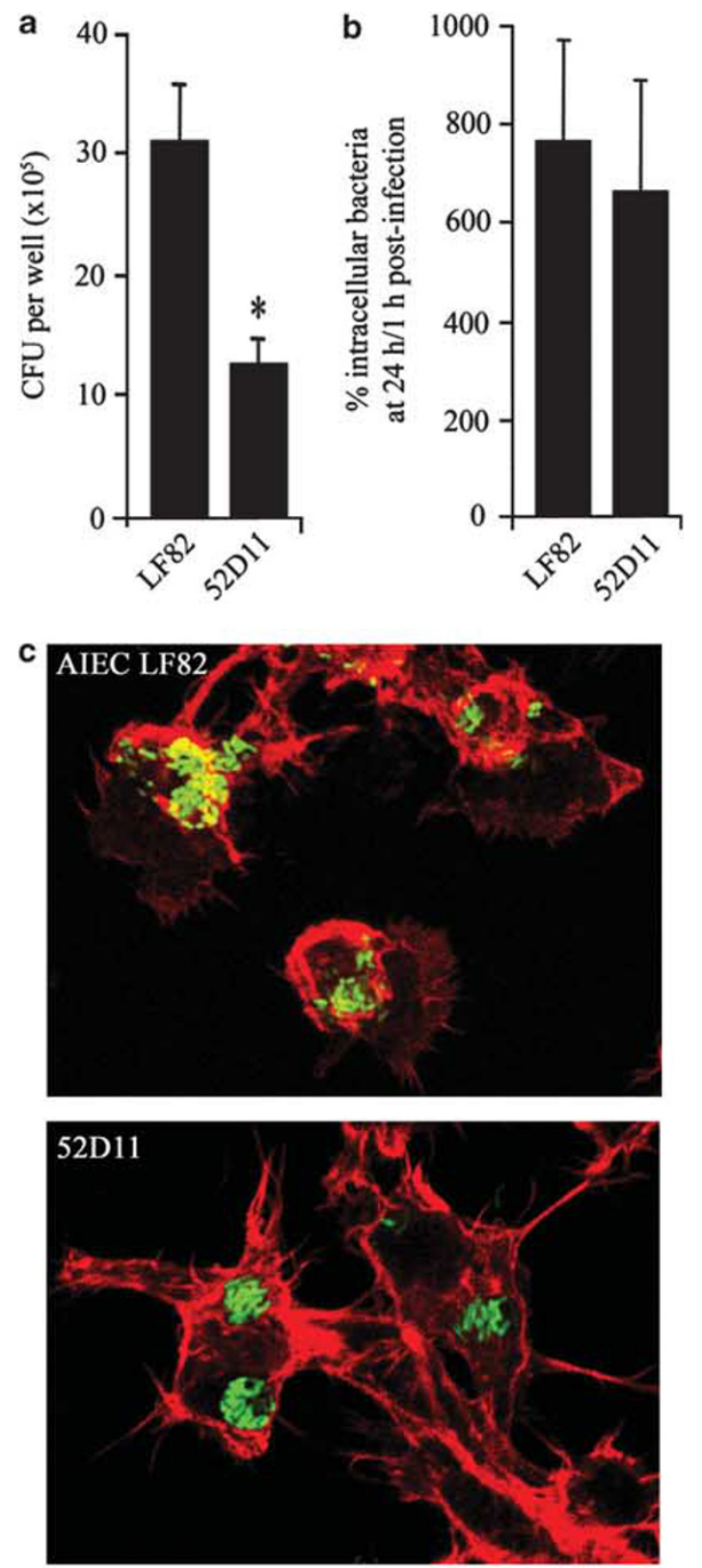

d

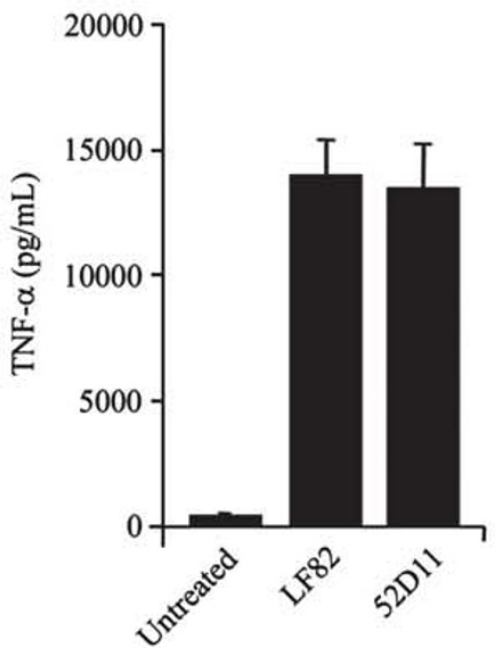

macrophages (Figure $4 \mathrm{~d}$ ). This suggests that the amount of TNF- $\alpha$ secreted is not related to the number of AIEC bacteria entering host cells but is correlated with AIEC intracellular replication.

\section{TNF- $\alpha$ Enhances the Intramacrophagic Replication of AIEC LF82 Bacteria}

We investigated whether TNF- $\alpha$ could favour the intracellular division of AIEC bacteria by measuring the number of intracellular bacteria at $24 \mathrm{~h}$ post infection following treatment of the AIEC LF82-infected macrophages with various concentrations of TNF- $\alpha$. Significant dose-dependent increases in intracellular AIEC LF82 bacteria were observed when infected macrophages were stimulated with exogenous TNF- $\alpha$ during the post-infection period (Figure 5a). Such increased number of intracellular bacteria within TNF- $\alpha$-treated macrophages does not result from an enhanced AIEC bacteria internalization within cells (Supplementary Figure S3a). Of note, when macrophages were treated with vacuolar $\mathrm{pH}$-neutralizing agents such as CQ or $\mathrm{NH}_{4} \mathrm{Cl}$, the increase in the number of intracellular LF82 bacteria within TNF- $\alpha$-treated macrophages was no longer observed (Figure 5d). For comparison, experiments were also performed with Salmonella enterica serovar Typhimurium, a pathogen known to replicate within macrophages and to induce TNF- $\alpha$ release by infected macrophages. The number of intracellular S. Typhimurium was determined at $1 \mathrm{~h}$ and $8 \mathrm{~h}$ post infection with untreated cells or macrophages treated with exogenous TNF- $\alpha$. Interestingly and in contrast to the results observed with AIEC bacteria, macrophage treatment with exogenous TNF- $\alpha$ did not modify the ability of $S$. Typhimurium to replicate within J774 macrophages (Figure 5b). TNF- $\alpha$ treatment did not also modify the ability of Salmonella to enter macrophages (Supplementary Figure S3b). These results suggest that the ability of exogenous TNF- $\alpha$ to enhance intramacrophagic replication is not a common feature of pathogenic bacteria. To define whether the enhanced AIEC intramacrophagic replication was unique to TNF- $\alpha$ stimulation, macrophages were treated with IFN- $\gamma$. We observed that the pre-treatment of macrophages with IFN $-\gamma$ induced the killing of $\sim 50 \%$ of intramacrophagic AIEC bacteria (Figure 5a), indicating that IFN- $\gamma$, a cytokine known to

Figure 4 Tumour necrosis factor-alpha (TNF- $\alpha$ ) secretion by macrophages infected with type1 pili-negative AIEC LF82 mutant. (a) Uptake of the AIEC strain LF82 and the non-piliated LF82 mutant (52D11 mutant). Results are expressed in colony forming units (CFU) per well at $1 \mathrm{~h}$ post infection.

(b) Bacterial survival and replication at $24 \mathrm{~h}$ post infection. Results are expressed as the number of intracellular bacteria at $24 \mathrm{~h}$ post infection relative to that obtained at $1 \mathrm{~h}$ post infection, taken as $100 \%$. (c) Confocal microscopy examinations of cells infected with GFP-expressing bacteria at $24 \mathrm{~h}$ post infection. The actin cytoskeleton of cells was stained using TRITClabelled phalloidin. (d) TNF- $\alpha$ secretion by AIEC LF82- or 52D11-infected macrophages. TNF- $\alpha$ secretion was measured by enzyme-linked immunosorbent assay (ELISA) in cell supernatants at $24 \mathrm{~h}$ post infection. Data are means \pm s.e.m. ${ }^{\star} P<0.05$. 
a
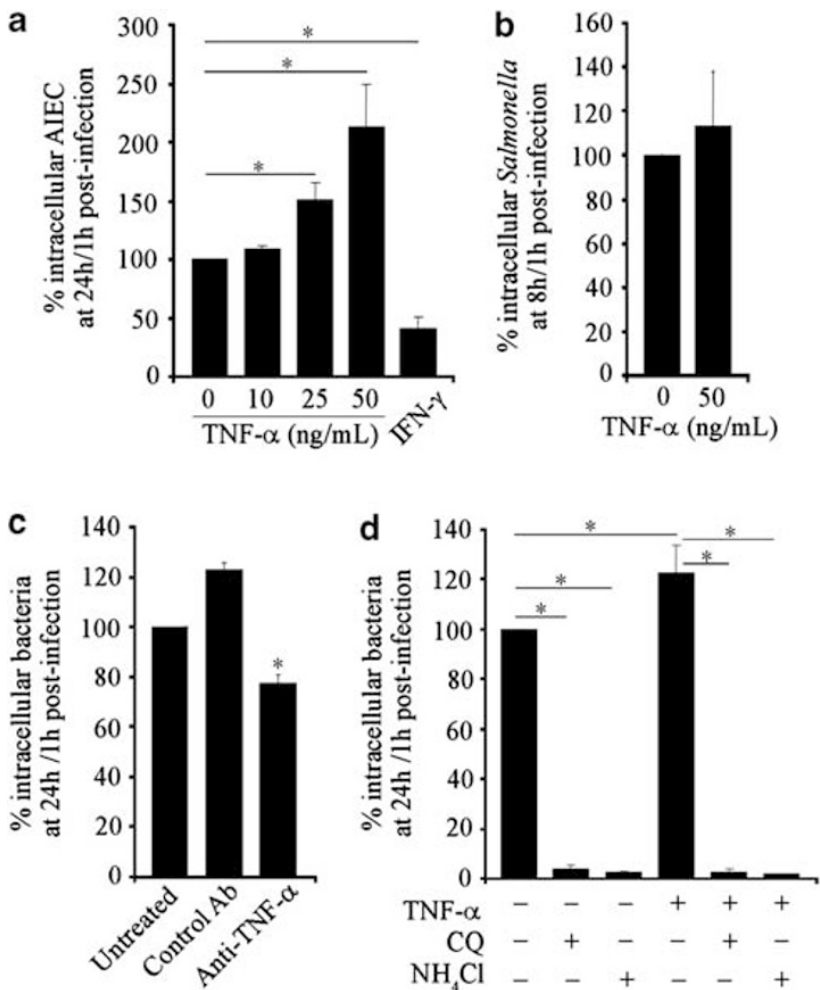

Figure 5 Role of TNF- $\alpha$ in the ability AIEC LF82 bacteria to replicate within macrophages. (a) Percentage of the number of intracellular AIEC bacteria at $24 \mathrm{~h}$ post infection relative to that obtained at $1 \mathrm{~h}$ post infection taken as $100 \%$, in untreated cells and cells stimulated with exogenous tumour necrosis factor-alpha (TNF- $\alpha$ ) at 10,25 or $50 \mathrm{ng} / \mathrm{ml}$ or IFN- $\gamma$ at $100 \mathrm{U} / \mathrm{ml}$. (b) Percentage of the number of intracellular $\mathrm{S}$. enterica serovar Typhimurium at $8 \mathrm{~h}$ post infection relative to that obtained at $1 \mathrm{~h}$ post infection taken as 100\%, in untreated cells and cells stimulated with exogenous TNF- $\alpha$ at $50 \mathrm{ng} / \mathrm{ml}$. (c) Percentage of the number of intracellular AIEC bacteria at $24 \mathrm{~h}$ post infection relative to that obtained at $1 \mathrm{~h}$ post infection taken as $100 \%$, in untreated cells and cells incubated with goat anti-mouse TNF- $\alpha$ antibodies, which were selected for their ability to neutralize the biological activity of TNF- $\alpha$, or isotype control antibodies (Control $\mathrm{Ab}$ ) at $1 \mu \mathrm{g} / \mathrm{ml}$. Antibodies were added during infection and post infection. (d) Percentage of the number of intracellular AIEC bacteria at $24 \mathrm{~h}$ post infection relative to that obtained at $1 \mathrm{~h}$ post infection taken as $100 \%$, in untreated cells and cells stimulated with exogenous TNF- $\alpha$ at $50 \mathrm{ng} / \mathrm{ml}$, and/or treated with chloroquine (CQ) at $10 \mu \mathrm{M}$ or ammonium chloride $\left(\mathrm{NH}_{4} \mathrm{Cl}\right)$ at $30 \mathrm{mM}$. All data are means \pm s.e.m. ${ }^{\star} P<0.05$.

enhance lysosomal function and bacterial killing, has opposite effect than that of TNF- $\alpha$ on intramacrophagic AIEC behaviour.

To provide further evidence that TNF- $\alpha$ has a positive effect on the intracellular replication of AIEC LF82 bacteria within macrophages, we treated infected cells with antiTNF- $\alpha$ antibodies. Results showed that neutralization of TNF- $\alpha$ secreted by infected macrophages using anti-TNF- $\alpha$ antibodies induced significant decrease in the number of intramacrophagic bacteria at $24 \mathrm{~h}$ post infection (Figure $5 \mathrm{c}$ ). As a control, treatment of macrophages with isotype control antibodies did not modify the number of intramacrophagic bacteria at $24 \mathrm{~h}$ post infection. The decrease in the numbers of intracellular bacteria observed at $24 \mathrm{~h}$ post infection after treatment with anti-TNF- $\alpha$ antibodies was not due to decreased internalization of AIEC bacteria (Supplementary Figure S3c). This reinforces our results demonstrating that TNF- $\alpha$ released by the infected macrophages favours intracellular replication of AIEC LF82 bacteria.

\section{DISCUSSION}

Increased colonization of the ileal mucosa by AIEC is

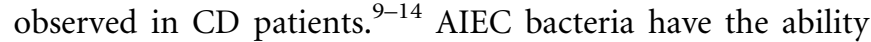
to survive and replicate within macrophages. ${ }^{23}$ They do not escape from the endocytic pathway but undergo normal interaction with host endomembrane organelles. AIEC bacteria replicate within acidic and cathepsin D-positive vacuolar phagolysosomes. ${ }^{24}$ We show here that AIECinfected macrophages secrete amounts of TNF- $\alpha$ according to the number of AIEC bacteria in contact with macrophages. Such TNF- $\alpha$ secretion correlated to the number of bacteria in contact with host cells has already been observed in the supernatant of macrophages infected with M. tuberculosis and L. pneumophila. ${ }^{30,42}$ However, secretion of TNF- $\alpha$ by infected monocytes/macrophages is not a common feature of pathogenic bacteria. Indeed, $\mathrm{TNF}-\alpha$ production is impaired following macrophage infection by Brucella spp., meningitidis-associated E. coli K1, and F. tularensis. ${ }^{27-29}$

In light of the observation that the amount of TNF- $\alpha$ secreted was correlated to the number of bacteria entering and replicating within macrophages two hypotheses emerged: either the amount of TNF- $\alpha$ released is directly related to extracellular PRR stimulation by bacteria in contact with host cells or it is due to the intracellular PRR stimulation by AIEC bacteria surviving and highly replicating within macrophages, or both. Comparison of amounts of TNF- $\alpha$ released by macrophages infected with live or killed bacteria revealed that TNF- $\alpha$ secretion in response to AIEC infection is dependent on extracellular PRR stimulation but also on intramacrophagic AIEC bacteria stimulation. In addition, when the number of AIEC bacteria entering macrophages was decreased by treating cells with endocytosis inhibitors no significant modifications in the level of secreted TNF- $\alpha$ was observed.

To determine whether AIEC replication inside active phagolysosomes was directly responsible for the TNF- $\alpha$ secretion we treated macrophages with the lysosomotropic agents CQ, a drug already used successfully in the treatment of $\mathrm{Q}$ fever by restricting intracellular $C$. burnetii replication within macrophages, ${ }^{43}$ and $\mathrm{NH}_{4} \mathrm{Cl}$, both drugs being able to neutralize intraphagosomal acid $\mathrm{pH}$. These drugs are also highly effective in limiting AIEC intramacrophagic replication, ${ }^{24}$ and in the present study we observed a subsequent decreased TNF- $\alpha$ secretion in response to AIEC infection in treated macrophages compared with untreated macrophages. As the decrease in TNF- $\alpha$ secretion could be due to treatments of macrophages with intravacuolar-neutralizing agents or to a decrease in the number of bacteria internalized in 
macrophages, we performed experiments with macrophages infected with the LF82- $\Delta h t r A$ isogenic mutant, which is not affected in its ability to enter macrophages but does not replicate intracellularly. ${ }^{37} \mathrm{~A}$ similar decreased amount of TNF- $\alpha$ released by macrophages infected with wild-type bacteria or the LF82- $\Delta h t r A$ isogenic mutant was observed. In addition, when macrophages were infected with the nonpiliated 52D11 mutant no changes in the amount of TNF- $\alpha$ released were observed. Of note for this type 1 pili mutant less bacteria are internalized within macrophages but they highly replicated within large vacuoles. Thus, these data indicated that in addition to TNF- $\alpha$ secreted due to stimulation of macrophages by extracellular AIEC bacteria, part of TNF- $\alpha$ secreted is due to intracellular AIEC replication. Such a result has a therapeutic potential as we can speculate that preventing internalization of AIEC bacteria does not appear as a good strategy to reduce TNF- $\alpha$ secretion whereas drugs able to control intramacrophagic bacteria replication could be efficient to limit TNF- $\alpha$ secretion.

TNF- $\alpha$ can have opposite effects on intracellular bacteria replication. For many intracellular pathogens the secretion of TNF- $\alpha$ by immune cells provides a suppressive environment. This has been well documented for L. pneumophila, C. burnetii and Brucella. Treatment of mouse macrophages or human monocytes with TNF- $\alpha$ inhibited the intracellular multiplication of L. pneumophila. ${ }^{34,35}$ It has been reported that C. burnetii replication in human monocytes involves the down-modulation of TNF- $\alpha .{ }^{33}$ In addition, TNF- $\alpha$ contributes to host resistance to intracellular Brucella at different stages of infection and exogeneously added TNF- $\alpha$ reduces the ability of Brucella to multiply within human macrophages. ${ }^{31,32}$ In contrast, TNF- $\alpha$ can favour intracellular bacteria replication. Indeed, supplementation of macrophages with exogenous TNF- $\alpha$ has been reported to accelerate the multiplication of intracellular $\mathrm{Myco-}$ bacterium. ${ }^{30}$ We show in the present study that in contrast to what we observed for S. enterica serovar Typhimurium, addition of exogenous TNF- $\alpha$ to AIEC-infected cells increased the number of intracellular bacteria and conversely AIEC-infected cells treated with antibodies that neutralize the bioactivity of TNF- $\alpha$ decreased the number of intracellular bacteria. In the opposite, treatment of macrophages with IFN- $\gamma$, a cytokine known to render macrophages more resistant to bacterial growth in part by enhancing lysosomal functions, induced AIEC bacteria killing.

The observation that TNF- $\alpha$ favours the intramacrophagic replication of AIEC bacteria suggests that TNF- $\alpha$ may not only harm the mucosa of $\mathrm{CD}$ patients but could also directly support the survival and/or replication of AIEC bacteria within macrophages. The mechanism by which TNF- $\alpha$ promotes AIEC intramacrophagic replication is still unclear. TNF- $\alpha$ is known to activate antiapoptotic signals. ${ }^{44}$ We can therefore speculate that TNF- $\alpha$ secreted by AIEC-infected macrophages together with AIEC infection by itself could interfere with apoptosis and thus prevent cell death and support the establishment of an intramacrophagic replication niche for AIEC bacteria. TNF- $\alpha$ is also reported to have a role in iron metabolism via the regulation of ferritin expression. ${ }^{45}$ Iron is required by bacteria for various metabolic processes that are crucial for microbial replication, including electron transport, glycolysis, DNA synthesis and defence against toxic reactive oxygen intermediates. ${ }^{46}$ To acquire iron, bacteria have developed specialized iron-uptake systems. Screening of the AIEC LF82 genome has revealed the presence of various iron-uptake systems. By increasing the availability of iron to AIEC bacteria, TNF- $\alpha$ could facilitate their growth. However, we have previously shown that exogenous iron supplementation of AIEC-infected macrophages does not enhance their intracellular replication. ${ }^{24}$ Finally, as AIEC bacteria inhabit in a phagolysosome and as the acid $\mathrm{pH}$ of this compartment is required for the intramacrophagic AIEC bacteria replication, ${ }^{24,37,47}$ the way in which TNF- $\alpha$ favours the survival and/or replication of AIEC bacteria could be related to the ability of TNF- $\alpha$ to enhance phagosome maturation and to induce phagosome acidification. Interestingly, similar results to those we observed with AIEC bacteria were previously reported with $M$. tuberculosis. In macrophages infected with $M$. tuberculosis, anti-TNF- $\alpha$ monoclonal antibodies inhibited Mycobacterium-containing phagosome acidification and limited the replication of intramacrophagic mycobacteria. $^{48}$

In conclusion, TNF- $\alpha$ is used by AIEC bacteria as a Trojan horse in order to increase their replication within macrophages. An amplification loop exists between TNF- $\alpha$ secretion and AIEC intramacrophagic replication as intracellular replication of AIEC bacteria induces the release of TNF- $\alpha$, and TNF- $\alpha$ increases the intracellular replication of AIEC. This study gives new insights into an approach to control AIEC replication within macrophages.

Supplementary Information accompanies the paper on the Laboratory Investigation website (http://www.laboratoryinvestigation.org)

\section{ACKNOWLEDGEMENTS}

We thank Amélie Devallée for technical assistance and Olivier Bardot for his help with confocal microscopy. The confocal microscope was property of ICCF, IFR79 Université d'Auvergne.This study was supported by grants from the Ministère de la Recherche et des Technologies (JE2526) and from INRA (USC 2018) and by grants from the Association F. Aupetit (AFA).

\section{DISCLOSURE/CONFLICT OF INTEREST}

The authors declare no conflict of interest.

1. Strober W, Fuss I, Mannon P. The fundamental basis of inflammatory bowel disease. J Clin Invest 2007;117:514-521.

2. Xavier RJ, Podolsky DK. Unravelling the pathogenesis of inflammatory bowel disease. Nature 2007;448:427-434.

3. Hampe J, Franke A, Rosenstiel $P$, et al. A genome-wide association scan of nonsynonymous SNPs identifies a susceptibility variant for Crohn disease in ATG16L1. Nat Genet 2007;39:207-211.

4. Massey DC, Parkes M. Genome-wide association scanning highlights two autophagy genes, ATG16L1 and IRGM, as being significantly associated with Crohn's disease. Autophagy 2007;3:649-651. 
5. Parkes $M$, Barrett JC, Prescott NJ, et al. Sequence variants in the autophagy gene IRGM and multiple other replicating loci contribute to Crohn's disease susceptibility. Nat Genet 2007;39:830-832.

6. Rioux JD, Xavier RJ, Taylor KD, et al. Genome-wide association study identifies new susceptibility loci for Crohn disease and implicates autophagy in disease pathogenesis. Nat Genet 2007;39: 596-604.

7. Hugot JP, Chamaillard M, Zouali $\mathrm{H}$, et al. Association of NOD2 leucinerich repeat variants with susceptibility to Crohn's disease. Nature 2001;411:599-603.

8. Ogura $\mathrm{Y}$, Bonen DK, Inohara $\mathrm{N}$, et al. A frameshift mutation in NOD2 associated with susceptibility to Crohn's disease. Nature 2001;411:603-606.

9. Baumgart $M$, Dogan $B$, Rishniw $M$, et al. Culture independent analysis of ileal mucosa reveals a selective increase in invasive Escherichia coli of novel phylogeny relative to depletion of Clostridiales in Crohn's disease involving the ileum. ISME 2007;1:403-418.

10. Darfeuille-Michaud A, Boudeau J, Bulois $P$, et al. High prevalence of adherent-invasive Escherichia coli associated with ileal mucosa in Crohn's disease. Gastroenterology 2004;127:412-421.

11. Martin HM, Campbell BJ, Hart CA, et al. Enhanced Escherichia coli adherence and invasion in Crohn's disease and colon cancer. Gastroenterology 2004;127:80-93.

12. Martinez-Medina $M$, Aldeguer $X$, Lopez-Siles $M$, et al. Molecular diversity of Escherichia coli in the human gut: new ecological evidence supporting the role of adherent-invasive E. coli (AIEC) in Crohn's disease. Inflamm Bowel Dis 2009;15:872-882.

13. Sasaki M, Sitaraman SV, Babbin BA, et al. Invasive Escherichia coli are a feature of Crohn's disease. Lab Invest 2007;87:1042-1054.

14. Eaves-Pyles T, Allen CA, Taormina J, et al. Escherichia coli isolated from a Crohn's disease patient adheres, invades, and induces inflammatory responses in polarized intestinal epithelial cells. Int J Med Microbiol 2008;298:397-409.

15. Boudeau J, Glasser AL, Masseret E, et al. Invasive ability of an Escherichia coli strain isolated from the ileal mucosa of a patient with Crohn's disease. Infect Immun 1999;67:4499-4509.

16. Barnich N, Carvalho FA, Glasser AL, et al. CEACAM6 acts as a receptor for adherent-invasive $E$. coli, supporting ileal mucosa colonization in Crohn disease. J Clin Invest 2007;117:1566-1574.

17. Carvalho FA, Barnich N, Sivignon A, et al. Crohn's disease adherentinvasive Escherichia coli colonize and induce strong gut inflammation in transgenic mice expressing human CEACAM. J Exp Med 2009;206:2179-2189.

18. Chassaing B, Rolhion N, Vallee A, et al. Crohn disease-associated adherent-invasive E. coli bacteria target mouse and human Peyer's patches via long polar fimbriae. J Clin Invest 2011;121:966-975.

19. Brest $P$, Lapaquette $P$, Souidi $M$, et al. A synonymous variant in IRGM alters a binding site for miR-196 and causes deregulation of IRGM-dependent xenophagy in Crohn's disease. Nat Genet 2011; 43:242-245.

20. Lapaquette $P$, Glasser AL, Huett A, et al. Crohn's disease-associated adherent-invasive $E$. coli are selectively favoured by impaired autophagy to replicate intracellularly. Cell Microbiol 2010;12:99-113.

21. Cooney R, Baker J, Brain O, et al. NOD2 stimulation induces autophagy in dendritic cells influencing bacterial handling and antigen presentation. Nat Med 2010;16:90-97.

22. Flannagan RS, Cosio G, Grinstein S. Antimicrobial mechanisms of phagocytes and bacterial evasion strategies. Nat Rev Microbiol 2009;7:355-366.

23. Glasser AL, Boudeau J, Barnich N, et al. Adherent invasive Escherichia coli strains from patients with Crohn's disease survive and replicate within macrophages without inducing host cell death. Infect Immun 2001;69:5529-5537.

24. Bringer MA, Glasser AL, Tung CH, et al. The Crohn's disease-associated adherent-invasive Escherichia coli strain LF82 replicates in mature phagolysosomes within J774 macrophages. Cell Microbiol 2006;8: 471-484.

25. Navarre WW, Zychlinsky A. Pathogen-induced apoptosis of macrophages: a common end for different pathogenic strategies. Cell Microbiol 2000;2:265-273.
26. Meconi S, Vercellone A, Levillain $\mathrm{F}$, et al. Adherent-invasive Escherichia coli isolated from Crohn's disease patients induce granulomas in vitro. Cell Microbiol 2007:9:1252-1261.

27. Jubier-Maurin V, Boigegrain RA, Cloeckaert A, et al. Major outer membrane protein Omp25 of Brucella suis is involved in inhibition of tumor necrosis factor alpha production during infection of human macrophages. Infect Immun 2001;69:4823-4830.

28. Selvaraj SK, Prasadarao NV. Escherichia coli K1 inhibits proinflammatory cytokine induction in monocytes by preventing NF-kappaB activation. J Leukoc Biol 2005;78:544-554.

29. Telepnev M, Golovliov I, Grundstrom T, et al. Francisella tularensis inhibits Toll-like receptor-mediated activation of intracellular signalling and secretion of TNF-alpha and IL-1 from murine macrophages. Cell Microbiol 2003;5:41-51.

30. Engele M, Stossel E, Castiglione $\mathrm{K}$, et al. Induction of TNF in human alveolar macrophages as a potential evasion mechanism of virulent Mycobacterium tuberculosis. J Immunol 2002;168:1328-1337.

31. Caron E, Peyrard T, Kohler S, et al. Live Brucella spp. fail to induce tumor necrosis factor alpha excretion upon infection of U937-derived phagocytes. Infect Immun 1994;62:5267-5274.

32. Dornand J, Gross A, Lafont V, et al. The innate immune response against Brucella in humans. Vet Microbiol 2002;90:383-394.

33. Ghigo E, Capo C, Raoult D, et al. Interleukin-10 stimulates Coxiella burnetii replication in human monocytes through tumor necrosis factor down-modulation: role in microbicidal defect of $Q$ fever. Infect Immun 2001;69:2345-2352.

34. Matsiota-Bernard $\mathrm{P}$, Lefebre $\mathrm{C}$, Sedqui $\mathrm{M}$, et al. Involvement of tumor necrosis factor alpha in intracellular multiplication of Legionella pneumophila in human monocytes. Infect Immun 1993;61:4980-4983.

35. McHugh SL, Newton CA, Yamamoto $Y$, et al. Tumor necrosis factor induces resistance of macrophages to Legionella pneumophila infection. Proc Soc Exp Biol Med 2000;224:191-196.

36. Boudeau J, Barnich N, Darfeuille-Michaud A. Type 1 pili-mediated adherence of Escherichia coli strain LF82 isolated from Crohn's disease is involved in bacterial invasion of intestinal epithelial cells. Mol Microbiol 2001;39:1272-1284.

37. Bringer MA, Barnich N, Glasser AL, et al. HtrA stress protein is involved in intramacrophagic replication of adherent and invasive Escherichia coli strain LF82 isolated from a patient with Crohn's disease. Infect Immun 2005;73:712-721.

38. McClelland $\mathrm{M}$, Sanderson $\mathrm{KE}$, Spieth J, et al. Complete genome sequence of Salmonella enterica serovar Typhimurium LT2. Nature 2001;413:852-856.

39. Valdivia RH, Falkow S. Fluorescence-based isolation of bacterial genes expressed within host cells. Science 1997;277:2007-2011.

40. Lafont F, van der Goot FG. Oiling the key hole. Mol Microbiol 2005;56:575-577.

41. Veiga $E$, Cossart $P$. The role of clathrin-dependent endocytosis in bacterial internalization. Trends Cell Biol 2006;16:499-504.

42. Skerrett SJ, Martin TR. Roles for tumor necrosis factor alpha and nitric oxide in resistance of rat alveolar macrophages to Legionella pneumophila. Infect Immun 1996;64:3236-3243.

43. Maurin $\mathrm{M}$, Benoliel $\mathrm{AM}$, Bongrand $\mathrm{P}$, et al. Phagolysosomal alkalinization and the bactericidal effect of antibiotics: the Coxiella burnetii paradigm. J Infect Dis 1992;166:1097-1102.

44. Gaur U, Aggarwal BB. Regulation of proliferation, survival and apoptosis by members of the TNF superfamily. Biochem Pharmacol 2003;66:1403-1408.

45. Torti SV, Kwak EL, Miller SC, et al. The molecular cloning and characterization of murine ferritin heavy chain, a tumor necrosis factorinducible gene. J Biol Chem 1988;263:12638-12644.

46. Schaible UE, Kaufmann SH. Iron and microbial infection. Nat Rev Microbiol 2004;2:946-953.

47. Bringer MA, Rolhion N, Glasser AL, et al. The oxidoreductase DsbA plays a key role in the ability of the Crohn's disease-associated adherent-invasive Escherichia coli strain LF82 to resist macrophage killing. J Bacteriol 2007;189:4860-4871.

48. Harris J, Hope JC, Keane J. Tumor necrosis factor blockers influence macrophage responses to Mycobacterium tuberculosis. J Infect Dis 2008;198:1842-1850. 